\title{
A TOPOLOGY VIA $\omega$-LOCAL FUNCTIONS IN IDEAL SPACES
}

\author{
AHMAD AL-OMARI and HANAN AL-SAADI
}

\begin{abstract}
The class of $\omega$-closed subsets of a space $(X, \tau)$ was defined to introduce $\omega$-closed functions. The purpose of this paper to introduce the notion of $\omega$-local functions and to give some of its basic properties in an ideal topological space. Moreover, we define and investigate the $\omega$-compatible spaces.
\end{abstract}

MSC 2010. 54A05, 54C10.

Key words. Ideal, Kuratowski, local function, $\omega$-open set, compatible space.

\section{REFERENCES}

[1] A. Al-Omari and M.S.M. Noorani, Regular generalized $\omega$-closed sets, Int. J. Math. Math. Sci., 2007 (2007), Article 16292, 1-11.

[2] A. Al-Omari and M.S.M. Noorani, Contra- $\omega$-continuous and almost contra- $\omega-c o n-$ tinuous, Int. J. Math. Math. Sci., 2007 (2007), Article 040469, 1-13.

[3] A. Al-Omari and T. Noiri, Local closure functions in ideal topological spaces, Novi Sad J. Math., 43 (2013), 139-149.

[4] A. Al-Omari, T. Noiri, M.S. Noorani, Weak and strong forms of sT-continuous functions, Commun. Korean Math. Soc., 30 (2015), 493-504.

[5] A. Al-Omari, S. Modak and T. Noiri, On $\theta$-modifications of generalized topologies via hereditary classes, Commun. Korean Math. Soc., 31 (2016), 857-868.

[6] A. Al-Omari, T. Noiri and S. Modak, Paracompact spaces with m-structures, An. Univ. Oradea Fasc. Mat., 24 (2017), 155-162.

[7] H. Al-Saadi and A.Al-Omari, Some operators in ideal topological spaces, Missouri J. Math. Sci., 30 (2018), 1-13.

[8] K.Y. Al-Zoubi, On generalized $\omega$-closed sets, Int. J. Math. Math. Sci., 13 (2005), 20112021.

[9] E. Ekici, S. Jafari and S.P. Moshokoa, On a weaker form of $\omega$-continuity, An. Univ. Craiova Ser. Mat. Inform., 37 (2010), 38-46.

[10] M. Ganster, Some remarks on strongly compact spaces and semi compact spaces, Bull. Malays. Math. Sci. Soc., 10 (1987), 67-81.

[11] D. Jankovic and T.R. Hamlett, New topologies from old via ideals, Amer. Math. Monthly, 97 (1990), 295-310.

[12] H.Z. Hdeib, w-closed mapping, Rev. Colombiana Mat., 16 (1982), 65-78.

[13] H.Z. Hdeib, $\omega$-continuous functions, Dirasat Journal, 16 (1989), 136-142.

[14] K. Kuratowski, Topology I, Warszawa, 1933.

The authors wish to thank the referees for useful comments and suggestions.

DOI: $10.24193 /$ mathcluj.2018.2.01 
Received February 27, 2018

Accepted May 22, 2018
Al al-Bayt University

Faculty of Sciences

Department of Mathematics

P.O. Box 130095, Mafraq 25113, Jordan

E-mail: omarimutah1@yahoo.com

Umm Al-Qura University

Faculty of Applied Sciences

Department of Mathematics

P.O. Box 11155, Makkah 21955, Saudi Arabia

E-mail: hasa112@hotmail.com 